\title{
Variabilidade de genótipos de milho quanto à composição de carotenoides nos grãos
}

\author{
Wilton Soares Cardoso(1), Maria Cristina Dias Paes(2), João Carlos Cardoso Galvão(1), Sara de Almeida Rios ${ }^{(1)}$, \\ Paulo Evaristo de Oliveira Guimarães ${ }^{(2)}$, Robert Eugene Schaffert ${ }^{(2)}$ e Aluízio Borém ${ }^{(1)}$ \\ (1)Universidade Federal de Viçosa, Avenida P.H. Rolfs, s/no, CEP 36571-000 Viçosa, MG. E-mail: wiltonscardoso@yahoo.com.br, \\ jgalvao@ufv.br, sarariosss@yahoo.com.br, borem@ufv.br (2)Embrapa Milho e Sorgo, Caixa Postal 151, CEP 35701-970 Sete Lagoas, MG. \\ E-mail:mcdpaes@cnpms.embrapa.br, evaristo@cnpms.embrapa.br, schaffer@cnpms.embrapa.br
}

\begin{abstract}
Resumo-O objetivo deste trabalho foi caracterizar e avaliar a variabilidade quanto ao teor e perfil de carotenoides nos grãos de 134 genótipos de milho (Zea mays), com vistas à utilização em programas de biofortificação. Os materiais foram provenientes dos campos experimentais e do Banco Ativo de Germoplasma da Embrapa Milho e Sorgo, Sete Lagoas, MG. São cultivares e híbridos comerciais, linhagens-elite e outros acessos escolhidos com base na coloração amarelo-alaranjada do endosperma. A quantificação do teor de carotenoides totais, carotenos e xantofilas mono-hidroxilada e di-hidroxilada dos grãos foi realizada por método cromatográficoespectrofotométrico. As médias encontradas nos grãos foram $22,34 \mu \mathrm{g} \mathrm{g}^{-1}$ de carotenoides totais, $2,55 \mu \mathrm{g} \mathrm{g}^{-1} \mathrm{de}^{\mathrm{d}}$ carotenos, 3,86 $\mathrm{g} \mathrm{g} \mathrm{g}^{-1}$ de xantofilas mono-hidroxiladas e $15,93 \mu \mathrm{g} \mathrm{g}^{-1} \mathrm{de}$ xantofilas di-hidroxiladas. Os genótipos foram agrupados em 18 grupos pelo método de Tocher. O germoplasma da Embrapa possui potencial para ser usado em programas de desenvolvimento de linhagens de milho biofortificadas, quanto ao total de carotenoides pró-vitamina A.
\end{abstract}

Termos para indexação: Zea mays, biofortificação, carotenoides, melhoramento, vitamina A.

\section{Variability of maize genotypes for grain carotenoid composition}

\begin{abstract}
The objective of this work was to characterize 134 maize (Zea mays) genotypes, for carotenoids content and build a genetic profile to facilitate future breeding to increase grain nutritional value (biofortification). Seeds came from experimental fields and from the Banco Ativo de Germoplasma of Embrapa Milho e Sorgo, Sete Lagoas, MG, Brazil. The genotypes were commercial hybrids, varieties, and inbred lines developed by the Embrapa biofortification program and other accessions, chosen for their yellow-orange endosperm color. Total grain carotenoids, carotenes, xanthophylls (monohydroxylates and dihydroxylates) were determined by chromatographic-spectrophotometric methods. The detected averages were: $22.34 \mu \mathrm{g} \mathrm{g}^{-1}$ for total carotenoids, $2.55 \mu \mathrm{g} \mathrm{g}^{-1}$ for carotenes, $3.86 \mu \mathrm{g} \mathrm{g}^{-1}$ for monohydroxylated xanthophylls, and $15.93 \mu \mathrm{g} \mathrm{g}^{-1}$ for dihydroxylated xanthophylls. The genotypes variability was divided into 18 groups by the method of Tocher. The Embrapa germplasm has variability and potential for development of maize lines biofortified for total of provitamin A carotenoids.
\end{abstract}

Index terms: Zea mays, biofortification, carotenoid, breeding, vitamin A.

\section{Introdução}

A deficiência de vitamina A é a principal causa de cegueira no mundo. Atinge aproximadamente $21 \%$ das crianças, e o maior número de afetados vivem nos continentes asiático e africano (World Health Organization, 2002).

A biofortificação de alimentos básicos com substâncias que apresentam atividade pró-vitamina A é apontada como uma estratégia para a diminuição dessa deficiência em áreas onde o problema é endêmico. A biofortificação caracteriza-se pelo aumento no conteúdo de nutrientes nos alimentos, por meio de melhoramento genético convencional ou da engenharia genética (Pfeiffer \& McClafferty, 2007).

O programa de biofortificação de milho tem focado o aumento do teor de carotenoides 
com atividade pró-vitamínica $\mathrm{A}$, principalmente o betacaroteno, e o aumento dos teores de ferro e zinco, a fim de tornar disponível maior quantidade desses nutrientes na dieta (Welch, 2002).

Os carotenoides são uma família de mais de 600 compostos lipossolúveis encontrados nas plantas. São responsáveis pelas cores das folhas e dos frutos (Britton et al., 2004; Ambrósio et al., 2006). Cerca de 50 carotenoides possuem atividade pró-vitamina A. O betacaroteno é o que apresenta maior atividade pró-vitamínica. Alfacaroteno, betacriptoxantina e zeinoxantina também apresentam atividade pró-vitamínica (Rodriguez-Amaya, 2001).

O grão de milho, apesar de possuir menor concentração de carotenoides quando comparado a outros alimentos, é considerado uma espécie carotenogênica, ou seja, fonte de carotenoides (Rodriguez-Amaya, 2001). Os principais carotenoides encontrados nos amiloplastos do endosperma do grão de milho são classificados como xantofilas (luteína, betacriptoxantina e zeaxantina) e carotenos (betacaroteno, alfacaroteno e betazeacaroteno) (JanickBuckner et al., 1999). As xantofilas, luteína e zeaxantina encontram-se em maior concentração no grão $(90 \%)$, enquanto o betacaroteno perfaz a menor concentração (5\%) (Cabuela, 1971). Análises de nutrientes no milho mostram diferenças significativas na concentração de carotenoides totais (que varia de 0 a $68 \mu \mathrm{g} \mathrm{g}^{-1}$ ) e de carotenos (que varia de 0,0 a $4,1 \mu \mathrm{g} \mathrm{g}^{-1}$ ) (Blessin et al., 1963; Quackenbush et al., 1963; Berardo et al., 2004).

A variabilidade para teor e perfil de carotenoides é observada em cultivares e linhagens de milho, o que indica a possibilidade de melhoramento para aumento do teor de carotenos (Janick-Buckner et al., 1999).

O objetivo deste trabalho foi caracterizar e avaliar a variabilidade quanto ao teor e perfil de carotenoides de 134 genótipos de milho, com vistas à utilização em programa de biofortificação.

\section{Material e Métodos}

Foram selecionados 134 genótipos de milho, com base na coloração amarelo-alaranjada do endosperma, constituídos por 99 linhagens geradas para o programa de biofortificação: 540736, 540754, 540755, 540757, 570759, 540764, 540807, 540811, 540815, 540817, 540819, 540847, 540886, 540890, 540938, 540972, 540985, 540987, 540992, 540998, 541018, 541031,
541032, 541034, 541099, 541157, 541311, 541332, 541335, 540685-1, 540700-1, 540707-1, 540721-1, 540723-1, 540727-1, 540740-1, 540760-1, 540763-1, 540780-1, 540800-1, 540808-1, 540814-1, 540818-2, 540826-1, 540838-1, 540843-1, 540845-2, 540848-1, 540874-2, 540878-1, 540880-2, 540893-2, 540899-2, 540903-2, 540941-2, 540942-2, 540948-2, 540962-1, 540986-1, 540995-2, 541016-2, 541028-1, 541034-2, 541051-1, 541052-1, 541055-1, 541057-1, 541069-2, 541070-2, 541072-2, 541093-1, 541112-1, 541116-1, 541117-2, 541119-2, 541120-1, 541133-1, 54114-1, 541228-1, 541233-2, 541234-1, 541249-2, 541270-2, 541272-1, 541274-1, 541275-1, 541276-1, 541278-1, 541307-1, 541312-1, 541316-1, 541323-1, 541325-1, 541330-2, 541335-1, 541337-1, 541338-1, 541339-1, 541343-2; 24 acessos pertencentes à coleção núcleo do banco ativo de germoplasma (BAG) da Embrapa Milho e Sorgo: Amarelo de PE A2, Azteca IPA, BA 130, BA I Cateto (Ribeirão Preto) 4496, BR 400 Superdoce, Cateto Colômbia, Cateto São Simão, Cateto Sete Lagoas, CMS 03 Amarilo Cristalino, CMS Amarillo Del Bajio, CMS 01 Mezcla Amarilla, Composto Racial Dent. Amarelo I, GIN I Cateto Nortista, Maya XV, MG II Cateto, PA 105, Pira 006, Piranao UF 1, Pirapoca Amarelo, RS 572, Santa Inês, SC 014, SP 009, WP2 Amarelo Dent; dois híbridos comerciais: BRS 1001, BRS 2020; e nove cultivares comerciais provenientes do ensaio nacional de 2006: BR 473 cIII, BR São Francisco, BRS Caatingueiro, CMS 101, CMS 102, CMS 104, Fundacep 35, Missões e UFVM 100.

Os grãos de cada genótipo, com exceção dos acessos do BAG de milho, foram obtidos na safra 2005/2006. O plantio de cada acesso foi realizado nos campos experimentais da Embrapa Milho e Sorgo, localizada a $12 \mathrm{~km}$ de Sete Lagoas, MG $\left(1^{\circ} 28^{\prime} \mathrm{S}\right.$ e $44^{\circ} 15^{\prime} \mathrm{W}$, e altitude de $732 \mathrm{~m}$ ). Os plantios foram realizados em áreas isoladas para proteção contra grãos de pólen provenientes de outros acessos. O manejo da cultura foi realizado conforme recomendações técnicas para a região (Embrapa, 1996).

Os grãos dos acessos foram obtidos diretamente no BAG de milho da Embrapa Milho e Sorgo, armazenados em câmara. Foi coletada uma amostra representativa da totalidade dos grãos gerados por cada genótipo. As amostras de grãos foram previamente identificadas, moídas em micromoinho tipo ciclone modelo MA 020 (Marconi, Piracicaba, SP), acondicionadas em frascos 
de vidro com tampa, envoltos em papel alumínio, e armazenadas a $-20^{\circ} \mathrm{C}$ no laboratório de qualidade de grãos e forragens da Embrapa Milho e Sorgo, onde foram realizadas as análises químicas. As amostras foram protegidas da exposição à luz, oxigênio e choque térmico, tanto antes quanto após a moagem, a fim de se evitar a degradação dos compostos objetos de estudo.

A quantificação do teor de carotenoides totais, carotenos, xantofilas mono-hidroxiladas e xantofilas di-hidroxiladas foi realizada por método cromatográfico-espectrofotométrico, seguindo o protocolo descrito por Rodriguez-Amaya \& Kimura (2004). As análises foram conduzidas em duplicata. As leituras espectrofotométricas foram realizadas no espectrofotômetro Cary 50 Conc UV-Visible (Varian, Austrália).

Os resultados das análises químicas foram avaliados por análise multivariada, pelas técnicas de agrupamento e método de otimização de Tocher, utilizando como medida de dissimilaridade a distância Euclidiana Média.

Para compor a matriz de distância ou dissimilaridade, utilizando-se a distância euclidiana média, foram utilizados os dados padronizados de carotenoides totais, carotenos, xantofilas mono-hidroxiladas e xantofilas di-hidroxiladas.

Os resultados também foram analisados por meio de componentes principais, apresentados em dispersão gráfica, seguindo a formação de grupos identificados pelo agrupamento de Tocher. As análises estatísticas foram realizadas utilizando o programa GENES (Cruz, 2005).

Para estimativa do conteúdo de vitamina $\mathrm{A}$, foi considerado que toda fração caroteno encontrada nos genótipos analisados referia-se a betacaroteno $\mathrm{e}$ às xantofilas mono-hidroxiladas como sendo a betacriptoxantina. Assim, cada micrograma de betacaroteno foi convertido em $1 / 12$ de atividade equivalente de retinol (RAE) e cada micrograma de betacriptoxantina foi convertido em 1/24 de RAE (Institute of Medicine, 2001).

\section{Resultados e Discussão}

Houve variação no conteúdo de carotenoides totais $\left(9,46\right.$ a $42,84 \mu \mathrm{g} \mathrm{g} \mathrm{g}^{-1}$ ), carotenos (alfa e betacarotenos) $\left(0,88\right.$ a $\left.4,93 \mu \mathrm{g} \mathrm{g}^{-1}\right)$, xantofila monohidroxilada (betacriptoxantina) $\left(1,13\right.$ a $\left.7,22 \mu \mathrm{g} \mathrm{g}^{-1}\right)$ e xantofilas di-hidroxiladas (luteína e zeaxantina) $\left(5,55\right.$ a $\left.34,11 \mu \mathrm{g} \mathrm{g}^{-1}\right)$ (Tabela 1). As médias foram $22,34 \mu \mathrm{g} \mathrm{g}^{-1}$ de carotenoides totais, 2,55 $\mu \mathrm{g} \mathrm{g}^{-1} \mathrm{de}$ carotenos, $3,86 \mu \mathrm{g} \mathrm{g}^{-1}$ de xantofilas mono-hidroxiladas e $15,93 \mu \mathrm{g} \mathrm{g}^{-1}$ de xantofilas di-hidroxiladas. Os valores foram expressos em base úmida.

A linhagem 541332 e a linhagem 541312-1 apresentaram os maiores teores de carotenoides totais, 42,84 e $42,51 \mu \mathrm{g} \mathrm{g}^{-1}$, respectivamente, valores esses elevados quando comparados aos valores médios das cultivares brasileiras comerciais, como Assum Preto $\left(11,17 \mu \mathrm{g} \mathrm{g}^{-1}\right)$ e BR $473\left(9,17 \mu \mathrm{g} \mathrm{g}^{-1}\right)$, analisadas por Kimura et al. (2007), e BRS $1001\left(30,95 \mu \mathrm{g} \mathrm{g}^{-1}\right)$, analisada neste trabalho.

Foram observadas médias superiores para os genótipos BRS 1001, com a concentração de carotenos de $4,93 \mu \mathrm{g} \mathrm{g}^{-1}$, bem como para a linhagem 540755, com 7,22 $\mu \mathrm{g} \mathrm{g}^{-1}$ de xantofilas mono-hidroxiladas e a linhagem 541312-1, com concentração de $34,11 \mu \mathrm{g} \mathrm{g}^{-1}$ de xantofilas di-hidroxiladas.

Em trabalhos realizados para seleção de germoplasmas para biofortificação, o intervalo encontrado para carotenoides totais nos grãos de milho dos genótipos brasileiros foi superior àqueles reportados por Kurilich \& Juvik (1999) para germoplasma norteamericano $\left(0,15\right.$ a $\left.33,11 \mu \mathrm{g} \mathrm{g}^{-1}\right)$, e semelhante aos reportados por Hulshof et al. (2007), que na avaliação de materiais para biofortificação encontraram de 9,90 a $39,98 \mu \mathrm{g} \mathrm{g}^{-1}$ de carotenoides totais em 22 linhagens, em base seca. Entretanto, Weber (1987) encontrou de 16 a $77 \mu \mathrm{g} \mathrm{g}^{-1}$ (em base seca) de carotenoides totais nas linhagens que analisou. Estas informações indicam possível ganho de carotenoides em grãos de milho por meio do melhoramento genético de plantas.

As cultivares comerciais e os acessos avaliados apresentaram teores de carotenoides totais inferiores aos das linhagens-elite do programa de melhoramento de milho da Embrapa Milho e Sorgo, cuja seleção é realizada com base em características agronômicas. A amplitude dos primeiros grupos foi semelhante à reportada por Kurilich \& Juvik (1999).

Considerando que os maiores teores de carotenoides totais foram encontrados nos materiais pertencentes ao grupo das linhagens-elite, é importante o uso dessas linhagens, aliado à seleção pela intensidade de cor dos grãos (Kurilich \& Juvik, 1999), para a seleção de materiais destinados à geração de híbridos em programa de biofortificação do milho. Quanto à 
Tabela 1. Teor e perfil de carotenoides nos grãos de 134 genótipos de milho.

\begin{tabular}{|c|c|c|c|c|c|c|c|}
\hline Genótipos & $\begin{array}{l}\text { Carotenoides totais } \\
\qquad\left(\mu \mathrm{g} \mathrm{g}^{-1}\right)^{(1)}\end{array}$ & $\begin{array}{l}\text { Carotenos } \\
\left(\mu \mathrm{g} \mathrm{g}^{-1}\right)^{(1)}\end{array}$ & $\begin{array}{c}\text { Carotenos como } \\
\text { percentagem de } \\
\text { carotenoides totais }\end{array}$ & $\begin{array}{c}\text { Xantofilas } \\
\text { mono-hidroxiladas } \\
\left(\mu \mathrm{g} \mathrm{g}^{-1}\right)^{(1)}\end{array}$ & $\begin{array}{c}\text { Xantofilas } \\
\text { mono-hidroxiladas } \\
\text { como percentagem } \\
\text { de carotenoides totais }\end{array}$ & $\begin{array}{c}\text { Xantofilas } \\
\text { di-hidroxiladas } \\
\left(\mu \mathrm{g} \mathrm{g}^{-1}\right)^{(1)}\end{array}$ & $\begin{array}{c}\text { Xantofilas } \\
\text { di-hidroxiladas } \\
\text { como percentagem } \\
\text { de carotenoides totais }\end{array}$ \\
\hline 540736 & $21,83 \pm 0,50$ & $2,77 \pm 0,10$ & 12,70 & $3,41 \pm 0,05$ & 15,63 & $15,64 \pm 0,65$ & 71,67 \\
\hline 540754 & $22,03 \pm 0,37$ & $2,50 \pm 0,16$ & 11,36 & $4,22 \pm 0,03$ & 19,16 & $15,31 \pm 0,50$ & 69,48 \\
\hline 540755 & $28,29^{(2)}$ & $2,71^{(2)}$ & 9,59 & $7,22^{(2)}$ & 25,51 & $18,36^{(2)}$ & 64,90 \\
\hline 540757 & $26,50+1,32$ & $3,18 \pm 0,22$ & 12,01 & $4,99 \pm 0,19$ & 18,82 & $18,33 \pm 0,91$ & 69,17 \\
\hline 570759 & $32,06^{(2)}$ & $2,16^{(2)}$ & 6,74 & $5, \overline{77^{(2)}}$ & 17,99 & $24,13^{(2)}$ & 75,27 \\
\hline 540764 & $28,68 \pm 5,30$ & $3,37 \pm 0,17$ & 11,74 & $4,87 \pm 0,05$ & 16,99 & $20,44 \pm 5,08$ & 71,27 \\
\hline 540807 & $24,01 \pm 0,10$ & $3,11 \pm 0,07$ & 12,95 & $4,85 \pm 0,00$ & 20,20 & $16,05 \pm 0,04$ & 66,85 \\
\hline 540811 & $17,65 \pm 0,52$ & $2,66 \pm 0,13$ & 15,08 & $4,61 \pm 0,07$ & 26,11 & $10,38 \pm 0,46$ & 58,82 \\
\hline 540815 & $27,12 \pm 0,04$ & $2,49 \pm 0,07$ & 9,19 & $5,44 \pm 0,01$ & $\begin{array}{l}20,11 \\
20,06\end{array}$ & $19,18 \pm 0,03$ & 70,74 \\
\hline 540817 & $16,71 \pm 0,20$ & $1,99+0,07$ & 11,91 & $3,32 \pm 0,15$ & 19,86 & $11,40+0,28$ & 68,23 \\
\hline 540819 & $15,89 \pm 0,20$ & $1,52 \pm 0,04$ & 9,54 & $2,13 \pm 0,01$ & 13,40 & $12,25 \pm 0,23$ & 77,06 \\
\hline 540847 & $16,08 \pm 0,71$ & $2,34 \pm 0,19$ & 14,54 & $4,97 \pm 0,24$ & 30,90 & $8,77 \pm 0,29$ & 54,56 \\
\hline 540886 & $12,67 \pm 0,60$ & $1,21 \pm 0,05$ & 9,53 & $1,44 \pm 0,04$ & 11,33 & $10,03 \pm 0,50$ & 79,14 \\
\hline 540890 & $16,42 \pm 1,72$ & $2,73 \pm 0,02$ & 16,64 & $3,39 \pm 0,07$ & 20,65 & $10,30 \pm 1,80$ & 62,72 \\
\hline 540938 & $28,45 \pm 1,30$ & $2,17 \pm 0,18$ & 8,87 & $3,60 \pm 0,65$ & 14,77 & $21,86 \pm 1,60$ & 76,37 \\
\hline 540972 & $19,03 \pm 2,82$ & $1,81 \pm 0,27$ & 9,52 & $4,40 \pm 0,54$ & 23,13 & $12,81 \pm 2,01$ & 67,35 \\
\hline 540985 & $21,93 \pm 1,11$ & $2,59 \pm 0,32$ & 11,79 & $2,65 \pm 0,11$ & 12,06 & $16,70 \pm 0,90$ & 76,15 \\
\hline 540987 & $16,90 \pm 1,02$ & $2,28 \pm 0,21$ & 13,46 & $3,92 \pm 0,01$ & 23,17 & $10,71 \pm 0,80$ & 63,36 \\
\hline 540992 & $20,34 \pm 0,78$ & $3,27 \pm 0,13$ & 16,10 & $6,59 \pm 0,01$ & 32,38 & $10,48 \pm 0,67$ & 51,52 \\
\hline 540998 & $16,99 \pm 0,40$ & $2,03 \pm 0,04$ & 11,93 & $3,78 \pm 0,07$ & 22,26 & $11,18 \pm 0,37$ & 65,81 \\
\hline 541018 & $22,27 \pm 1,10$ & $1,98 \pm 0,04$ & 8,91 & $3,68 \pm 0,03$ & 16,53 & $16,61 \pm 1,10$ & 74,56 \\
\hline 541031 & $17,45 \pm 0,45$ & $2,48+0,01$ & 14,23 & $4,12 \pm 0,12$ & 23,62 & $10,85 \pm 0,32$ & 62,15 \\
\hline 541032 & $21,55 \pm 1,02$ & $2,47 \pm 0,02$ & 11,44 & $5,13 \pm 0,30$ & 23,81 & $13,96 \pm 0,74$ & 64,76 \\
\hline 541034 & $18,89 \pm 1,35$ & $2,12 \pm 0,28$ & 11,18 & $2,74 \pm 0,41$ & 14,51 & $14,03 \pm 0,66$ & 74,31 \\
\hline 541099 & $33,45 \pm 0,86$ & $3,41 \pm 0,05$ & 10,20 & $5,35 \pm 0,38$ & 16,00 & $24,69 \pm 0,43$ & 73,80 \\
\hline 541157 & $18,84 \pm 0,78$ & $2,82 \pm 0,19$ & 14,94 & $4,52 \pm 0,06$ & 23,99 & $11,50 \pm 0,53$ & 61,06 \\
\hline 541311 & $24,45 \pm 1,17$ & $2,56 \pm 0,03$ & 10,47 & $3,72 \pm 0,26$ & 15,22 & $18,17 \pm 0,87$ & 74,31 \\
\hline 541332 & $42,84 \pm 1,86$ & $4,11 \pm 0,01$ & 9,60 & $5,70 \pm 0,06$ & 13,31 & $33,02 \pm 1,80$ & 77,09 \\
\hline 541335 & $37,00 \pm 0,42$ & $3,28 \pm 0,01$ & 8,86 & $5,87 \pm 0,11$ & 15,85 & $27,86 \pm 0,51$ & 75,29 \\
\hline $540685-1$ & $26,60 \pm 1,23$ & $2,89 \pm 0,20$ & 10,85 & $3,58 \pm 0,12$ & 13,47 & $20,13 \pm 1,52$ & 75,68 \\
\hline $540700-1$ & $21,31 \pm 0,15$ & $2,22 \pm 0,29$ & 10,40 & $4,87 \pm 0,02$ & 22,83 & $14,23 \pm 0,46$ & 66,77 \\
\hline $540707-1$ & $26,24 \pm 0,92$ & $3,19 \pm 0,57$ & 13,84 & $4,53 \pm 0,15$ & 17,35 & $18,53 \pm 0,21$ & 68,81 \\
\hline $540721-1$ & $19,44 \pm 0,17$ & $2,97 \pm 0,30$ & 15,27 & $5,83 \pm 0,39$ & 30,01 & $10,64 \pm 0,52$ & 54,72 \\
\hline $540723-1$ & $17,19 \pm 0,25$ & $1,60 \pm 0,14$ & 9,31 & $2,76 \pm 0,15$ & 16,05 & $12,83 \pm 0,54$ & 74,64 \\
\hline $540727-1$ & $38,97 \pm 0,49$ & $4,35 \pm 0,35$ & 11,17 & $6,95 \pm 0,80$ & 17,84 & $27,66 \pm 0,66$ & 70,99 \\
\hline $540740-1$ & $15,32 \pm 1,47$ & $2,95 \pm 0,43$ & 19,30 & $4,01 \pm 0,22$ & 26,21 & $8,35 \pm 0,82$ & 54,49 \\
\hline $540760-1$ & $18,29 \pm 0,84$ & $1,40 \pm 0,19$ & 7,66 & $2,50 \pm 0,16$ & 13,69 & $14,39 \pm 0,48$ & 78,65 \\
\hline $540763-1$ & $23,95 \pm 0,51$ & $3,51 \pm 0,75$ & 11,01 & $5,41 \pm 0,20$ & 16,94 & $15,02 \pm 0,99$ & 72,06 \\
\hline $540780-1$ & $32,67 \pm 2,04$ & $3,54 \pm 0,05$ & 10,85 & $6,67 \pm 0,36$ & 20,43 & $22,45 \pm 1,73$ & 68,73 \\
\hline $540800-1$ & $18,23 \pm 0,89$ & $2,30 \pm 0,04$ & 12,59 & $3,38 \pm 0,09$ & 18,54 & $12,56 \pm 0,95$ & 68,87 \\
\hline 540808-1 & $23,42 \pm 0,19$ & $2,84 \pm 0,05$ & 12,14 & $4,30 \pm 0,29$ & 18,36 & $16,28 \pm 0,44$ & 69,50 \\
\hline 540814-1 & $25,29 \pm 2,75$ & $1,77 \pm 0,41$ & 6,99 & $3,59 \pm 0,16$ & 14,21 & $19,93 \pm 2,19$ & 78,80 \\
\hline $540818-2$ & $20,88 \pm 0,35$ & $2,46 \pm 0,00$ & 11,76 & $3,44 \pm 0,26$ & 16,49 & $14,98 \pm 0,09$ & 71,74 \\
\hline $540826-1$ & $32, \overline{30}^{(2)}$ & $3,92^{(2)}$ & 12,15 & $5,90^{(2)}$ & 18,28 & $22,47^{(2)}$ & 69,57 \\
\hline $540838-1$ & $20,56 \pm 0,56$ & $2,57 \pm 0,20$ & 12,51 & $4,57 \pm 0,22$ & 22,22 & $13,42 \pm 0,13$ & 65,27 \\
\hline 540843-1 & $17,05 \pm 0,09$ & $2,34 \pm 0,09$ & 13,75 & $4,49 \pm 0,16$ & 26,33 & $10,21 \pm 0,16$ & 59,92 \\
\hline $540845-2$ & $10,83 \pm 0,39$ & $1,06 \pm 0,00$ & 9,83 & $3,05 \pm 0,05$ & 28,21 & $6,71 \pm 0,33$ & 61,96 \\
\hline 540848-1 & $19, \overline{49}^{(2)}$ & $2,26^{(2)}$ & 11,61 & $5, \overline{32} 2^{(2)}$ & 27,30 & $11,90^{(2)}$ & 61,09 \\
\hline 540874-2 & $26,19 \pm 0,67$ & $3,75 \pm 0,09$ & 14,31 & $5,44 \pm 0,12$ & 20,79 & $17,00 \pm 0,64$ & 64,90 \\
\hline $540878-1$ & $21,77 \pm 0,59$ & $3,87 \pm 0,12$ & 17,79 & $3,95 \pm 0,38$ & 18,16 & $13,94 \pm 0,86$ & 64,05 \\
\hline $540880-2$ & $20,46 \pm 1,26$ & $2,69 \pm 0,02$ & 13,15 & $2,74 \pm 0,05$ & 13,41 & $15,02 \pm 1,34$ & 73,45 \\
\hline $540893-2$ & $26,58 \pm 0,36$ & $2,79 \pm 0,06$ & 10,49 & $3,94 \pm 0,14$ & 14,83 & $19,85 \pm 0,56$ & 74,68 \\
\hline 540899-2 & $24,84 \pm 0,03$ & $2,58 \pm 0,13$ & 10,41 & $4,11 \pm 0,18$ & 16,54 & $18,14 \pm 0,34$ & 73,05 \\
\hline 540903-2 & $26,10 \pm 0,14$ & $2,92 \pm 0,04$ & 11,17 & $3,72 \pm 0,57$ & 14,24 & $19,46 \pm 0,75$ & 74,59 \\
\hline $540941-2$ & $27,11 \pm 1,32$ & $2,05 \pm 0,01$ & 7,57 & $4,22 \pm 0,02$ & 15,58 & $20,83 \pm 1,34$ & 76,84 \\
\hline $540942-2$ & $20,24^{(2)}$ & $1,23^{(2)}$ & 6,06 & $2, \overline{69}^{(2)}$ & 13,27 & $16,33^{(2)}$ & 80,67 \\
\hline $540948-2$ & $24,68 \pm 1,49$ & $3,41 \pm 0,00$ & 13,81 & $6,19 \pm 0,25$ & 25,10 & $15,07 \pm 1,74$ & 61,08 \\
\hline $540962-1$ & $22,34 \pm 0,84$ & $2,18 \pm 0,12$ & 9,74 & $3,53 \pm 0,09$ & 15,81 & $16,63 \pm 1,05$ & 74,45 \\
\hline 540986-1 & $24,09 \pm 1,61$ & $2,86 \pm 0,01$ & 11,85 & $5,18 \pm 0,22$ & 21,50 & $16,06 \pm 1,82$ & 66,65 \\
\hline 540995-2 & $16,33 \pm 0,70$ & $2,69 \pm 0,05$ & 16,49 & $4,26 \pm 0,24$ & 26,10 & $9,37 \pm 0,41$ & 57,41 \\
\hline $541016-2$ & $25,81 \pm 0,31$ & $3,63 \pm 0,06$ & 14,06 & $2,57 \pm 0,01$ & 9,97 & $19,61 \pm 0,36$ & 75,97 \\
\hline $541028-1$ & $15,82 \pm 0,12$ & $2,53 \pm 0,41$ & 16,02 & $3,70 \pm 0,61$ & 23,39 & $9,59 \pm 1,13$ & 60,59 \\
\hline $541034-2$ & $18,13 \pm 0,28$ & $2,64+0,06$ & 14,55 & $4,14 \pm 0,16$ & 22,83 & $11,35 \pm 0,50$ & 62,61 \\
\hline $541051-1$ & $35,15 \pm 1, \overline{68}$ & $3,83 \pm 0,25$ & 10,90 & $4,49 \pm 0,22$ & 12,77 & $26,83 \pm 1,70$ & 76,34 \\
\hline $541052-1$ & $38,86 \pm 0,74$ & $4,13 \pm 0,15$ & 10,63 & $4,53 \pm 0,07$ & 11,65 & $30,20 \pm 0,82$ & 77,72 \\
\hline $541055-1$ & $39,37 \pm 1,91$ & $3,92 \pm 0,15$ & 9,96 & $5,20 \pm 0,35$ & 13,21 & $30,25 \pm 1,41$ & 76,83 \\
\hline $541057-1$ & $27,37 \pm 1,56$ & $1,73 \pm 0,15$ & 6,33 & $2,84 \pm 0,23$ & 10,36 & $22,80 \pm 1,18$ & 83,31 \\
\hline $541069-2$ & $27,13 \pm 0,85$ & $4,19 \pm 0,02$ & 15,44 & $4,81 \pm 0,10$ & 17,75 & $18,13 \pm 0,73$ & 66,81 \\
\hline
\end{tabular}


Tabela 1. Continuação.

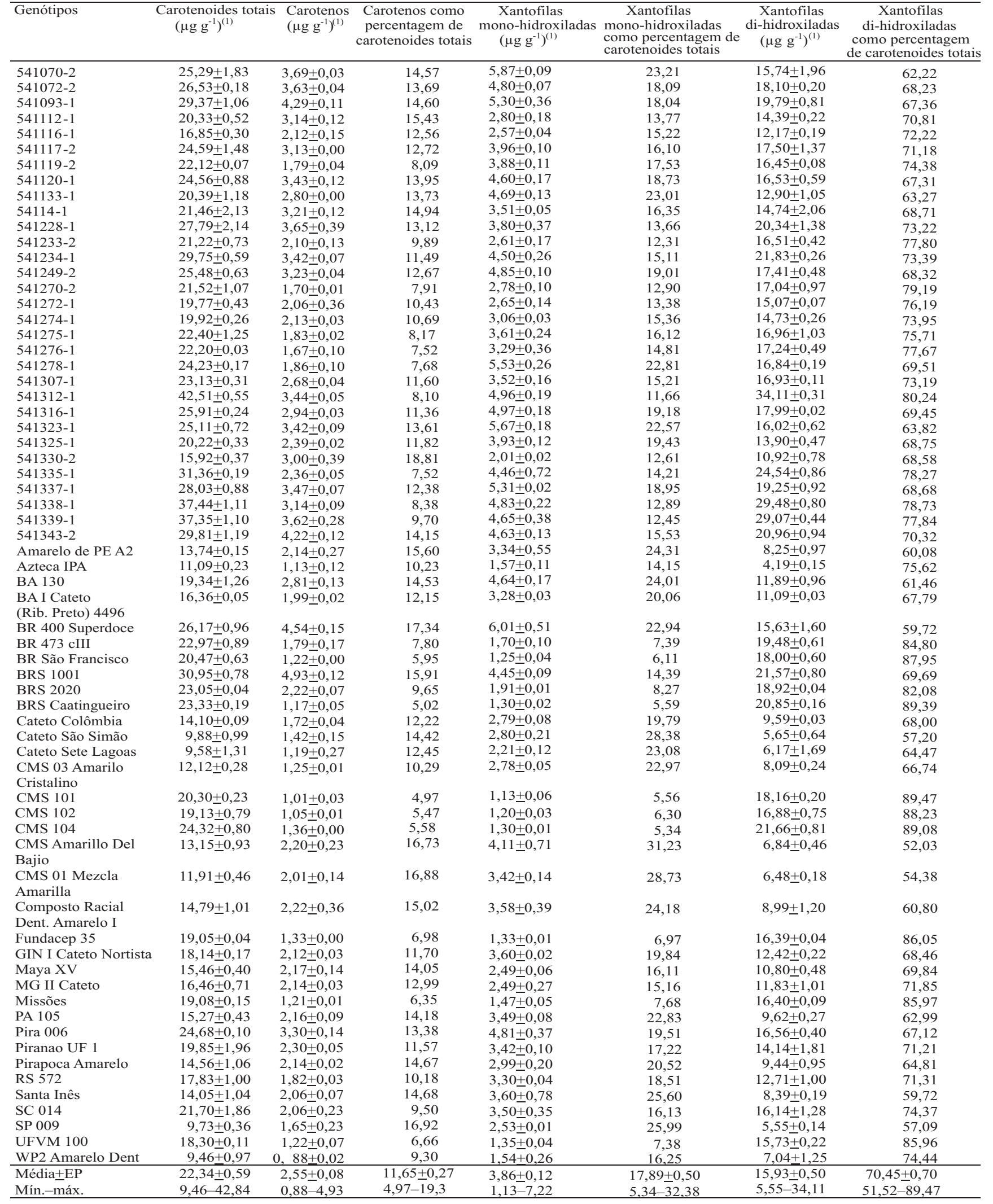

${ }^{(1)} \mathrm{O}$ valor é a média de duas replicatas_EP (erro-padrão), expresso em base úmida. ${ }^{(2)}$ Amostra insuficiente para replicata. 
seleção pela intensidade de cor dos grãos, no entanto, segundo Pfeiffer \& McClafferty (2007) a coloração visual do grão de milho é dominada por carotenoides que não possuem atividade pró-vitamina $\mathrm{A}$, luteína $\mathrm{e}$ zeaxantina (xantofilas di-hidroxiladas). Uma seleção somente por cor pode ser aplicada para separar grãos brancos ou levemente amarelos dos grãos de cores amarelo-intenso ou laranja.

$\mathrm{O}$ conteúdo médio de caroteno foi de $2,55 \mu \mathrm{g} \mathrm{g}^{-1}$, e a proporção média de carotenos, em relação ao total de carotenoides nos genótipos estudados, foi de $11 \%$. Os maiores percentuais não foram observados nas linhagens e sim no híbrido comercial BRS 1001 e no acesso BR 400 superdoce. Os resultados médios para carotenos estão abaixo dos relatados em outros trabalhos. Hulshof et al. (2007) encontraram valores de 0,85 a $12,75 \mu \mathrm{g} \mathrm{g}^{-1}$ (em base seca) para total de carotenos, e Kurilich \& Juvik (1999) encontraram valores de até $7,64 \mu \mathrm{g} \mathrm{g}^{-1}$ para betacaroteno, em base seca. Embora haja diferença entre os métodos empregados e as substâncias quantificadas, a fração carotenos é constituída basicamente de betacaroteno, o que permite a comparação dos resultados desses estudos.

A fração de xantofila mono-hidroxilada (betacriptoxantina), que também possui atividade pró-vitamina $\mathrm{A}$, apresentou média de $3,86 \mu \mathrm{g} \mathrm{g}^{-1}$ $(17,89 \%$ de proporção média). Altos valores de xantofila mono-hidroxilada são desejáveis para melhorar a quantidade de vitamina A no milho (Pfeiffer \& McClafferty, 2007). O melhor resultado para conteúdo de carotenoides pró-vitamina A foi da linhagem 540727-1, com 11,30 $\mu \mathrm{g} \mathrm{g}^{-1}$ (carotenos mais xantofila mono-hidroxilada), em base úmida, muito próximo ao resultado obtido por
Hulshof et al. (2007), de 14,77 $\mu \mathrm{g} \mathrm{g}^{-1}$, em base seca, e superior ao valor de $8,90 \mu \mathrm{g} \mathrm{g}^{-1}$, em base seca, obtido por Kurilich \& Juvik (1999). De acordo com esses resultados, pode-se considerar que o germoplasma de milho da Embrapa possui potencial para conteúdo de carotenoides pró-vitamina A.

$\mathrm{Na}$ estimativa do conteúdo de vitamina $\mathrm{A}$, foram escolhidos os materiais com as dez maiores e as dez menores RAE em $100 \mathrm{~g}$ do material (Tabela 2).

Os genótipos de maior teor de vitamina A apresentaram uma média de RAE de 58,3 por $100 \mathrm{~g}$, valor quase cinco vezes maior que o de outros genótipos, o que evidencia grande variabilidade para essa característica. As linhagens constituíram a maioria dos genótipos com alto teor de vitamina $\mathrm{A}$, o que demonstra ganho para essa característica obtido no Programa de Biofortificação da Embrapa. Apenas o híbrido BRS 1001 e o acesso BR 400 apresentaram também alto valor de RAE.

Entre os genótipos com baixa RAE, destacam-se sete cultivares comerciais, o que confirma a necessidade de liberação comercial de novos materiais pelos programas de melhoramento.

O Institute of Medicine (2001) preconiza uma ingestão diária de vitamina A equivalente a 900 RAE por adultos do sexo masculino com idade entre 19 e 50 anos, e a 400 RAE por crianças na faixa etária de 4 a 8 anos. Para atingir esses valores, é necessário o consumo, respectivamente, de $1.385 \mathrm{~g}$ e $615 \mathrm{~g}$ de farinha de milho integral da linhagem 540727-1, que teve o maior valor de RAE (65 RAE por $100 \mathrm{~g}$ de farinha).

As correlações de Pearson entre as frações de carotenoides analisadas fazem sentido biológico, pois a via de biossíntese de carotenoides dos compostos

Tabela 2. Dez genótipos de milho com maiores e dez genótipos com menores conteúdos de vitamina A nos grãos. Os valores estão calculados em atividade equivalente de retinol (RAE) por $100 \mathrm{~g}$ de milho. $1 \mathrm{RAE}=12 \mu \mathrm{g}$ de betacaroteno e $24 \mu \mathrm{g}$ de carotenoides pró-vitamínicos.

\begin{tabular}{|c|c|c|c|}
\hline $\begin{array}{l}\text { Genótipos com menores } \\
\text { conteúdos }\end{array}$ & $\begin{array}{l}\text { Teor de vitamina A (RAE por } \\
100 \mathrm{~g} \text { de milho integral) }\end{array}$ & $\begin{array}{l}\text { Genótipos com maiores } \\
\text { conteúdos }\end{array}$ & $\begin{array}{c}\text { Teor de vitamina A (RAE } \\
\text { por } 100 \mathrm{~g} \text { de milho integral) }\end{array}$ \\
\hline CMS 101 & 13,1 & 540992 & 54,7 \\
\hline WP2 Amarelo & 13,7 & $541069-2$ & 55,0 \\
\hline CMS 102 & 13,7 & $541070-2$ & 55,2 \\
\hline BRS Caatingueiro & 15,2 & $540826-1$ & 57,3 \\
\hline BR São Francisco & 15,4 & $540780-1$ & 57,3 \\
\hline UFVM 100 & 15,8 & $541093-1$ & 57,8 \\
\hline Azteca IPA & 16,0 & 541332 & 58,0 \\
\hline 540886 & 16,1 & BRS 1001 & 59,6 \\
\hline Missões & 16,2 & BR 400 Superdoce & 62,8 \\
\hline Fundacep 35 & 16,6 & $540727-1$ & 65,2 \\
\hline
\end{tabular}


analisados está na mesma rota metabólica (Dellapenna \& Pogson, 2006; Quinlan et al., 2007). Houve forte correlação das frações carotenos, xantofilas monohidroxiladas e xantofilas di-hidroxiladas com os carotenoides totais (Tabela 3). Essa correlação indica que existe considerável variação alélica entre os genes que controlam a biossíntese destes compostos. Isto sugere que os níveis das frações carotenoides podem ser simultaneamente aumentados, em relação aos carotenoides totais (Kurilich \& Juvik, 1999).

A matriz de distância euclidiana média foi utilizada para o agrupamento dos genótipos pelo método de Tocher. Houve a formação de 18 grupos, sendo o maior deles com 55 componentes, e nove grupos com apenas um genótipo, o que indica variabilidade para essa característica no germoplasma estudado, embora haja muitos genótipos semelhantes para a composição de carotenoides no grão de milho.
Os grupos gerados pelo método de Tocher facilitam a seleção de material divergente para compor o melhoramento por meio da geração de híbridos, principalmente as linhagens-elite, uma vez que permitem a seleção de genótipos pertencentes a grupos heteróticos distintos a serem indicados para cruzamento. A combinação complementar do perfil de carotenoides, através de hibridização, aumenta significativamente o conteúdo desses nutrientes (Egesel et al., 2003).

Em um programa de melhoramentoé importantea escolha de genótipos promissores, o que permite obter híbridos com maior produção e também possibilita a formação de boas populações para a extração de linhagens. No agrupamento Tocher (Tabela 4), podem-se selecionar genótipos promissores para geração de híbridos, como o grupo 3 que poderia ser cruzado com o genótipo do grupo 16.

O método de componentes principais (Figura 1), também foi utilizado para avaliar a dispersão do

Tabela 3. Correlações de Pearson entre as frações de carotenoides analisadas em grãos de 134 genótipos de milho.

\begin{tabular}{|c|c|c|c|}
\hline Variáveis & Carotenos & Xantofilas mono-hidroxiladas & Xantofilas di-hidroxiladas \\
\hline Carotenoides totais & $0,6784^{*}$ & $0,5652^{*}$ & $0,9628^{*}$ \\
\hline Carotenos & - & $0,7191 *$ & $0,4930^{*}$ \\
\hline Xantofilas mono-hidroxiladas & - & - & $0,3350 *$ \\
\hline
\end{tabular}

*Correlações significativas a 5\% de probabilidade, pelo teste $\mathrm{t}$.

Tabela 4. Agrupamento dos 134 genótipos de milho quanto ao teor e perfil de carotenoides de grãos, segundo método de Tocher.

\begin{tabular}{|c|c|c|}
\hline Grupos & $\mathrm{N}^{\mathrm{o}}$ de componentes & Componentes \\
\hline 1 & 55 & $\begin{array}{l}\text { 540736, 540754, 540811, 540817, 540890, 540938, 540972, 540985, 540987, 540998, 541018, 541031, 541034, } \\
541157,541311,540700-1,540723-1,540763-1,540800-1,540808-1,540818-2,540838-1,540843-1,540880-2, \\
540962-1,540995-2,541028-1,541034-2,541112-1,541116-1,541119-2,541133-1,54114-1,541233-2,541270-2, \\
\text { 541272-1, 541274-1, 541275-1, 541276-1, 541307-1, 541325-1, Amarelo de PE A2, BA 130, } \\
\text { BA I Cateto (Rib. Preto) 4496, Cateto Colombia, Composto Racial Dent. Amarelo I, GIN I Cateto Nortista, } \\
\text { Maya XV, MG II Cateto, PA 105, Piranao UF 1, Pirapoca Amarelo, RS 572, Santa Inês, SC 014 }\end{array}$ \\
\hline 2 & 13 & $\begin{array}{l}\text { 540819, 540760-1, 540942-2, BR } 473 \text { cIII, BR São Francisco, BRS 2020, BRS Caatingueiro, CMS 101, CMS 102, } \\
\text { CMS 104, Fundacep 35, Missões, UFVM } 100\end{array}$ \\
\hline 3 & 26 & $\begin{array}{l}540757,540764,540807,540815,540685-1,540707-1,540874-2,540893-2,540899-2,540903-2,540948-2, \\
540986-1,541069-2,541070-2,541072-2,541093-1,541117-2,541120-1,541228-1,541234-1,541249-2, \\
541316-1,541323-1,541337-1,541343-2, \text { Pira } 006\end{array}$ \\
\hline 4 & 9 & $\begin{array}{l}\text { 540886, 540845-2, Azteca IPA, Cateto São Simão, Cateto Sete Lagoas, CMS } 03 \text { Amarilo Cristalino, } \\
\text { CMS 01Mezcla Amarilla, SP 009, WP2 Amarelo Dent }\end{array}$ \\
\hline 5 & 5 & $540847,540992,541032,540721-1,540848-1$ \\
\hline 6 & 9 & $541099,541332,541335,541051-1,541052-1,541055-1,541312-1,541338-1,541339-1$ \\
\hline 7 & 4 & $540814-1,540941-2,541057-1,541335-1$ \\
\hline 8 & 2 & $540780-1,540826-1$ \\
\hline 9 & 2 & 540740-1, CMS Amarillo del Bajio \\
\hline 10 & 1 & $541330-2$ \\
\hline 11 & 1 & $540878-1$ \\
\hline 12 & 1 & $541278-1$ \\
\hline 13 & 1 & $541016-2$ \\
\hline 14 & 1 & BR 400 Superdoce \\
\hline 15 & 1 & 540755 \\
\hline 16 & 1 & 570759 \\
\hline 17 & 1 & BRS 1001 \\
\hline 18 & 1 & $540727-1$ \\
\hline
\end{tabular}


germoplasma estudado. No cálculo dos coeficientes de ponderação (autovetores) associados às características avaliadas, determinados pelo programa GENES (Cruz, 2005), a ordem das variáveis de maior peso foi: carotenoides totais, carotenos, xantofilas monohidroxiladas e xantofilas di-hidroxiladas. Os dois primeiros componentes principais explicaram cerca de $93 \%$ da variação total.

Ainda na Figura 1, pode-se verificar a dispersão dos genótipos. As cores representam os grupos formados pelo método de agrupamento de Tocher. A dispersão dos genótipos permite concluir que o agrupamento Tocher foi bem estabelecido para alguns materiais, visto que eles estão visualmente separados dos demais, a exemplo dos grupos verde e amarelo. Outros genótipos encontram-se misturados a outros grupos, não sendo possível fazer uma distinção pela visualização no gráfico.

A avaliação da divergência genética com auxílio de análises multivariada pode ser uma ferramenta adicional na escolha dos genitores, para a obtenção das melhores combinações híbridas (Melo et al., 2001), não somente para aumento de produção, mas também para o incremento de componentes secundários, como os carotenoides.

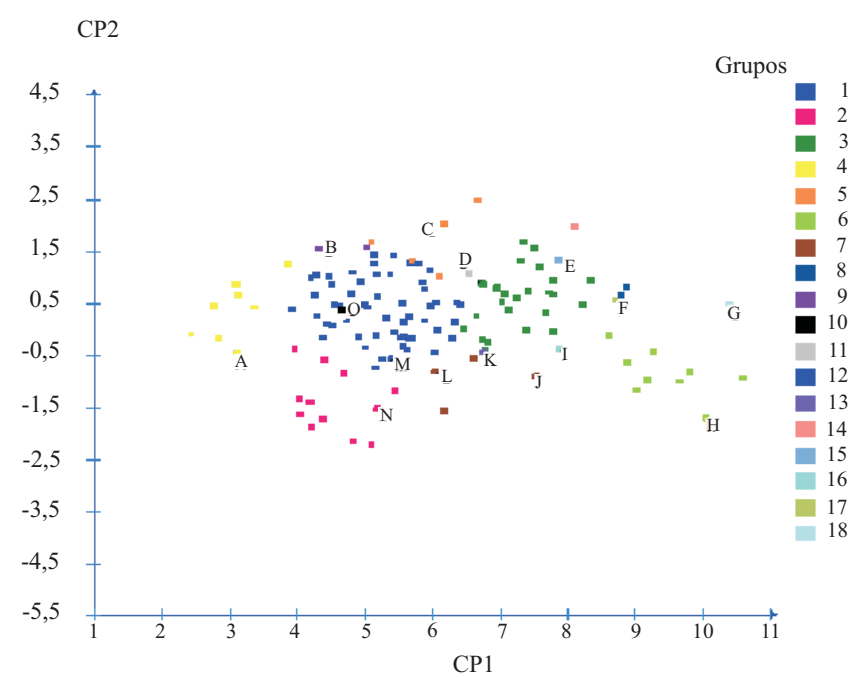

Figura 1. Dispersão gráfica de genótipos de milho avaliados quanto aos teores de carotenoides no grão, com base nos dois primeiros componentes principais. Os grupos 1 a 18 correspondem aos grupos descritos na Tabela 4. Genótipos: A, 540886; B, CMS Amarillo Del Bajio; C, 540721-1; D, 540878-1; E, 540755; F, BRS 1001; G, 540727-1; H, 541312-1; I, 570759; J, 541335-1; K, 541016-2; L, 540814-1; M, 541276-1, N, BR 473 cIII; O, 541330-2.

\section{Conclusões}

1. Existe variabilidade para perfil e teor de carotenoides nos grãos do germoplasma de milho estudado, o que evidencia seu potencial para o melhoramento genético para a biofortificação.

2. O germoplasma de milho da Embrapa Milho e Sorgo possui potencial para o desenvolvimento de linhagens biofortificadas, principalmente quanto ao total de carotenoides pró-vitamina A.

\section{Agradecimentos}

Ao Challenge Program Generation - Harvest Plus, e à Fundação de Amparo à Pesquisa do Estado de Minas Gerais, pelo apoio financeiro.

\section{Referências}

AMBRÓSIO, C.L.B.; CAMPOS, F. de A.C. e S.; FARO, Z.P. de. Carotenóides como alternativa contra a hipovitaminose A. Revista Nutrição, v.19, p.233-243, 2006.

BERARDO, N.; BRENNA, O.V.; AMATO, A.; VALOTI, P.; PISACANE; V.; MOTTO, M. Carotenoids concentration among maize genotypes measured by near infrared reflectance spectroscopy (NIRS). Innovative Food Science and Emerging Technologies, v.5, p.393-398, 2004.

BLESSIN, C.W.; BRECHER, J.D.; DIMLER, R.J. Carotenoids of corn and sorghum. 5. Distribution of xanthophylls and carotenes in hand-dissected and dry-milled fractions of yellow dent corn. Cereal Chemistry, v.40, p.582-586, 1963.

BRITTON, G.; LIAAEN-JENSEN, S.; PFANDER, H. Carotenoids handbook. Basel: Birkauser Verlag. 2004. 562p.

CABUELA, I. Contribution to the study of carotenoids metabolism in the maize grain. In: MEETING OF THE MAIZE AND SORGHUM SECTION OF EUCARPIA, 5., 1971, Budapest. Proceedings. Budapest: Akademiai Kiado, 1971. p.85-91.

CRUZ, C.D. Programa GENES: aplicativo computacional em genética e estatística. Viçosa: Imprensa Universitária, 2005. 648p.

DELLAPENNA, D.; POGSON, B.J. Vitamin synthesis in plants: tocopherols and carotenoids. Annual Review of Plant Biology, v.57, p.711-738, 2006.

EGESEL, C.O.; WONG, J.C.; LAMBERT, R.J.; ROCHEFORD, T.R. Combining ability of maize inbreds for carotenoids and tocopherols. Crop Science, v.43, p.818-823, 2003.

EMBRAPA. Centro Nacional de Pesquisa de Milho e Sorgo. Recomendações técnicas para o cultivo do milho. 2.ed. Brasília: Embrapa-SPI; Sete Lagoas: Embrapa-CNPMS, 1996. 204p.

HULSHOF, P.J.M.; KOSMEIJER-SCHUIL, T.; WEST, C.E.; HOLLMAN, P.C.H. Quick screening of maize kernels for provitamin A content. Journal of Food Composition and Analysis, v.20, p.655-661, 2007. 
INSTITUTE OF MEDICINE. Dietary reference intakes for vitamin $A$, vitamin $K$, arsenic, boron, chromium, copper, iodine, iron, manganese, molybdenium, nickel, silicon, vanadium and zinc. Washington, DC: National Academy Press, 2001. 797p.

JANICK-BUCKNER, D.; HAMMOCK, D.J.; JOHNSON, J.M.; OSBORN, J.M.; BUCKNER, B. Biochemical and ultrastructural analysis of the y10 mutant of maize. Journal of Heredity, v.90, p.507-513, 1999.

KIMURA, M.; KOBORI, C.N.; RODRIGUEZ-AMAYA, D.B.; NESTEL, P. Screening and HPLC methods for carotenoids in sweet potato, cassava and maize for plant breeding trials. Food Chemistry, v.100, p.1734-1746, 2007.

KURILICH, A.C.; JUVIK, J.A. Quantification of carotenoid and tocopherol antioxidants in Zea mays. Journal of Agricultural and Food Chemistry, v.47, p.1948-1955, 1999.

MELO, W.M.C.; PINHO, R.G.V.; FERREIRA, D.F. Capacidade combinatória e divergência genética em híbridos comerciais de milho. Ciência e Agrotecnologia, v.25, p.821-830, 2001.

PFEIFFER, W.H.; MCCLAFFERTY, B. HarvestPlus: breeding crops for better nutrition. Crop Science, v.47, p.88-105, 2007.

QUACKENBUSH, F.W.; BRUNSON, A.M.; HOUSE, L.R.; FIRCH, J.G. Carotenoid, oil, and tocopherol content of corn inbreds. Cereal Chemistry, v.40, p.250-259, 1963.
QUINLAN, R.F.; JARADAT, T.T.; WURTZEL, E.T. Escherichia coli as a platform for functional expression of plant $\mathrm{P} 450$ carotene hydroxylases. Archives of Biochemistry and Biophysics, v.458, p.146-157, 2007.

RODRIGUEZ-AMAYA, D.B. A guide to carotenoid analysis in foods. Washington, DC: International Life Sciences Institute, 2001. 64p.

RODRIGUEZ-AMAYA, D.B.; KIMURA, M. HarvestPlus handbook for carotenoid analysis. Washington, DC: International Food Policy Research Institute; Cali: International Center for Tropical Agriculture, 2004. 58p. (Technical monograph series, 2).

WEBER, E.J. Carotenoids and tocols of corn grain determined by HPLC. Journal of the American Oil Chemists Society, v.64, p.1129-1134, 1987.

WELCH, R.M. Breeding strategies for biofortified staple plant foods to reduce micronutrient malnutrition globally. Journal of Nutrition, v.132, p.495-499, 2002.

WORLD HEALTH ORGANIZATION. The world health report: childhood and maternal undernutrition. Genebra: WHO, 2002. cap.4. Disponível em: <http://www.who.int/whr/2002/en/whr02_ ch4.pdf>. Acesso em: 27 abr. 2006.

Recebido em 30 de setembro de 2008 e aprovado em 29 de janeiro de 2009 